\title{
Electron Channeling Contrast Observations in Deformed Magnesium Alloys
}

\author{
Shirin Kaboli, Hendrix Demers, Nicolas Brodusch and Raynald Gauvin \\ Department of Mining and Materials Engineering, McGill University, Montréal, Canada
}

In industrial metal-forming processes, quantitative and physical models are required to control and optimize the microstructure of the finished products. A detailed understanding of the behavior of polycrystalline materials during deformation processes is essential to develop such models. A number of instruments and analytical tools are available for deformation studies within the microscopy and microanalysis community. In a scanning electron microscope (SEM), the visualization and characterization of deformed microstructures are carried out with electron channeling contrast imaging (ECCI) and electron backscattered diffraction (EBSD). These SEM studies provide a nanoscale spatial resolution, a large field of view and statistically reliable information on a bulk specimen [1]. In this study, complex variations of backscattering intensity $\left(\mathrm{I}_{\mathrm{BSE}}\right)$ were observed in ECCI micrographs of magnesium $(\mathrm{Mg})$ grains after the uniaxial hot compression test. The variations of IBSE across the ECCI micrographs were attributed to plastic deformation of the $\mathrm{Mg}$ grains [2]. Recovery, recrystallization and phase transformation processes occurred simultaneously during deformation at high temperature. The interactions between the three processes lead to a complex deformed microstructure consisting of dynamically recrystallized grains and precipitates. The deformed microstructure varied with different deformation variables such as temperature, strain rate and strain $[3,4]$.

A uniaxial hot compression test was carried out on a polycrystalline $\mathrm{Mg}$-Al-Ca alloy specimen using the MTS servo-hydraulic testing machine. The tests were performed at $350^{\circ} \mathrm{C}$, strain rate of $0.01 \mathrm{~s}^{-1}$ and 0.1 , 0.6 strains. A Hitachi IM-3000 flat ion milling system and a Hitachi ZONESEM sample surface cleaning were used for specimen surface preparation. A Hitachi SU-8000 cold-field emission SEM was used to study the deformed microstructure.

The secondary electron micrographs of Mg-Al-Ca alloy specimens after the uniaxial hot compression test are shown in Figure 1. At 0.1 strain, the microstructure consists of $\mathrm{Mg}$ parent grains with internal subgrain boundaries and extensive serrations at original grain boundaries (Fig. 1a). At 0.6 strain, a duplex microstructure was observed consisting of elongated parent grains surrounded with equiaxed dynamically recrystallized grains. Parent grains were elongated perpendicular to the compression axis to accommodate deformation during the uniaxial hot-compression test (Fig. 1b). Results of ECCI for the same specimens are shown in Figure 2. Complex variations of $\mathrm{I}_{\mathrm{BSE}}$ were observed in bright and dark regions across these micrographs. Variations in width and electron channeling contrast of these regions were observed with a tilt of the stage or a change in electron beam energy. These examinations indicated a crystallographic origin for the variations of $\mathrm{I}_{\mathrm{BSE}}$ inside grains. Similar electron channeling contrast observations in the form of irregular dark and bright bands running across the width of the deformed grains were previously reported [2]. The channeling contrast observations in ECCI micrographs were described as follows. In a polycrystalline material subjected to a deformation test, grains deform in a complex and inhomogeneous manner. Each grain is subjected to microscopic constrains from neighboring grains in addition to the macroscopic applied stress. During a hot compression test on a $\mathrm{Mg}-\mathrm{Al}-\mathrm{Ca}$ alloy, a regular change in orientation occurred across the $\mathrm{Mg}$ grains due to bending of the lattice planes [2]. In ECCI, the angle between the lattice planes and electron beam varied during the scanning action on the specimen surface which resulted in complex variations of the $\mathrm{I}_{\mathrm{BSE}}$ across the micrograph. 


\section{References:}

[1] D. C. Joy, D. E. Newbury, D.E. \& D. L. Davidson, J. Appl. Phys. 53(1982), pp. 81-122.

[2] D. C. Joy et al, Proceedings of the 5th annual scanning electron microscope symposium part I and part II, workshop on biological specimen preparation for scanning electron microscopy, (1972), pp. 97 104.

[3] F. J. Humphreys in "Recrystallization and related annealing phenomena", ed. M. Hatherly, (Pergamon, Oxford, Tarrytown), (1995), p.11.

[4] S. Kaboli et al, IOP Conference Series: Materials Science and Engineering, European Microbeam Analysis Society (EMAS), (2013), (Accepted).
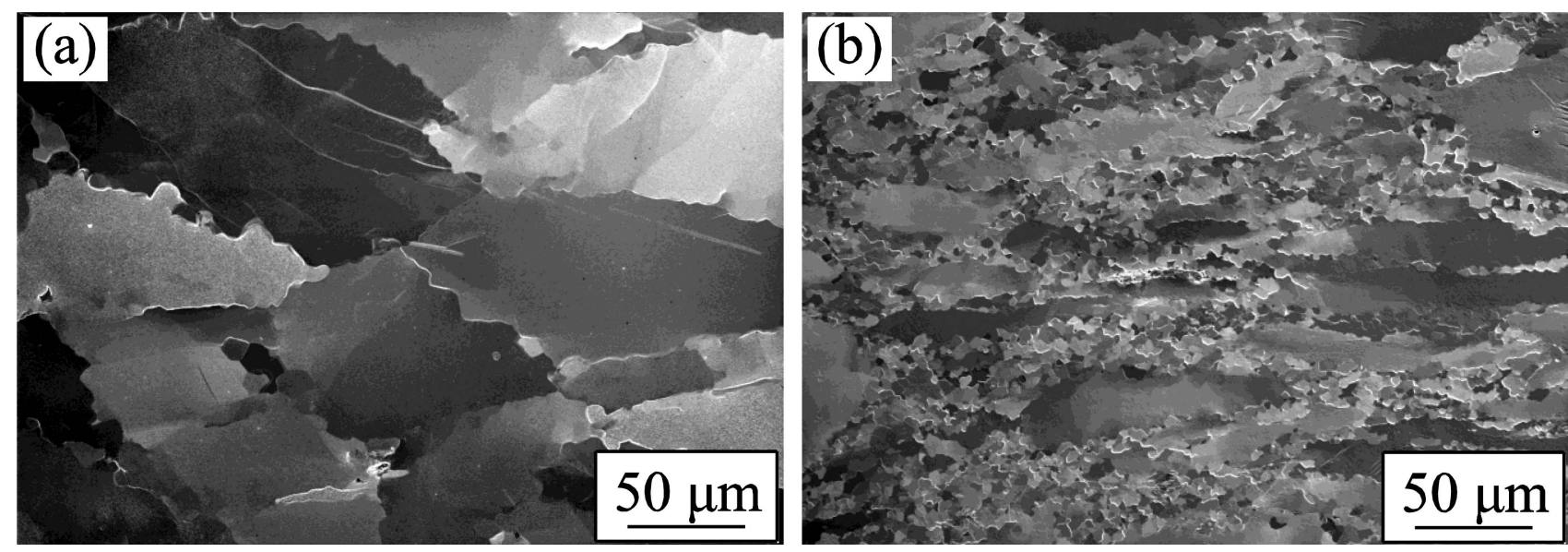

Figure 1. The Mg-Al-Ca alloy microstructure after the uniaxial hot compression test. Secondary electron micrographs of deformed specimen at (a) 0.1 strain and (b) 0.6 strain. The compression axis was aligned along the vertical direction of the micrographs. Parent grains were elongated perpendicular to the compression axis to accommodate deformation during the uniaxial hotcompression test.
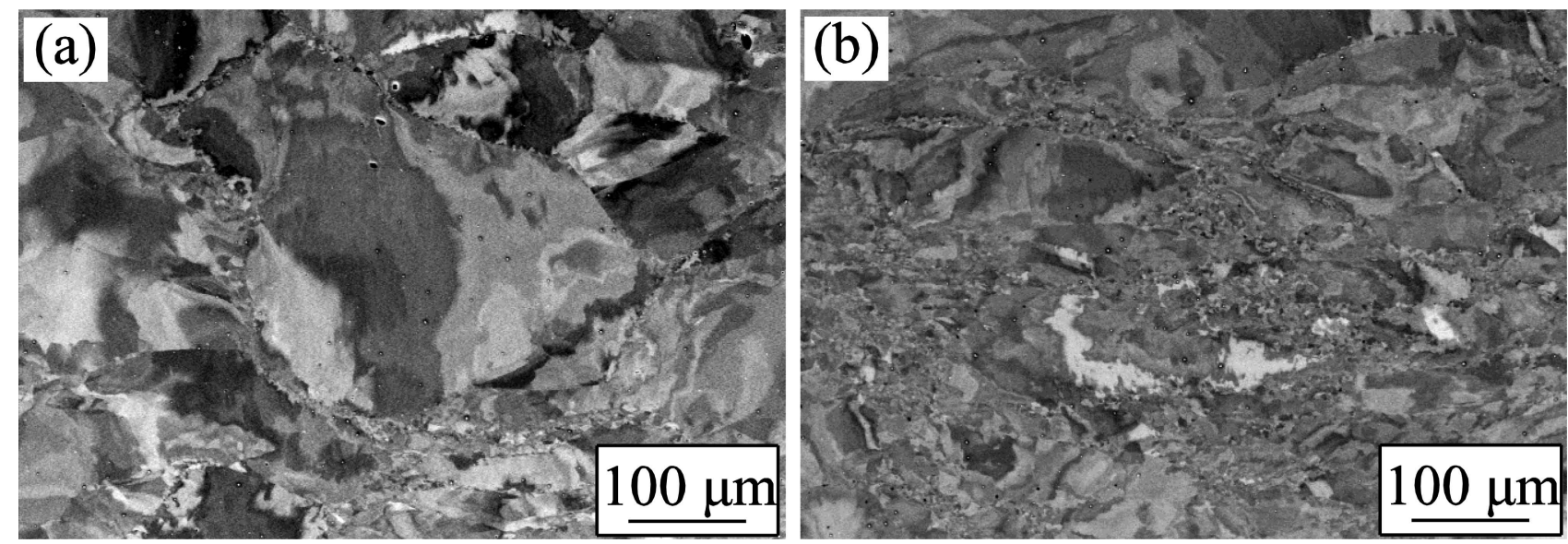

Figure 2. The Mg-Al-Ca alloy microstructure after the uniaxial hot compression test. Backscattered electron micrographs of deformed specimen at (a) 0.1 strain and (b) 0.6 strain. The compression axis was aligned along the vertical direction. Complex channeling contrast was observed in bright and dark regions across the micrographs. 